\title{
CONSTITUIÇÃO E FORMAÇÃO DO SUJEITO ADMINISTRADOR
}

\author{
CONSTITUTION AND FORMATION OF MANAGERS
}

\author{
Recebido em: 15/02/2013 Aprovado em: 18/04/2013 \\ Avaliado pelo sistema double blind review
}

Editora Científica: Manolita Correia Lima

\section{SUSANE PETINELLI-SOUZA susipetinelli@gmail.com UNIVERSIDADE FEDERAL DO ESPÍRITO SANTO}

\begin{abstract}
RESUMO
O estudo analisa a constituição e a formação do sujeito administrador. Os materiais e a análise foram organizados em torno de três eixos: eixo das subjetividades, eixo dos poderes e eixo dos saberes. Os eixos são produções teórico-empíricas, pois neles estão as análises das entrevistas e as teorias, além das análises da formação em Administração que ocorriam com base em documentos, legislação e elementos históricos. As entrevistas foram realizadas com professores que lecionam no curso de Administração, alunos em vias de formação e administradores recém-egressos. Não se pretendeu produzir uma nova verdade sobre a formação em administração, mas, mapear as condições de emergência dos sujeitos administradores e de sua formação. Dentre as condições mapeadas estão os modos pelos quais somos governados, ou seja, os modelos de conduta que estão pautados nos modos de ação empresariais, a profissionalização da área, a sistematização do ensino e a constituição de um campo de conhecimento.

Palavras-chaves: formação; curso de Administração; poder; saber; subjetividades.
\end{abstract}

\begin{abstract}
The aim of this work is to analyze the constitution and education of managers. The materials and analysis were organized around three lines: subjectivity, power and knowledge. The lines are theoretical-empirical productions, since they contain the analyses of the interviews and theories, as well as the analysis of the education in this course based on documents, legislation and historical elements. The interviews were conducted with business administration teachers and senior students, as well as recently graduated managers. The intention was not to produce a new truth about the education in this course, but to map the conditions for the emergence of managers and their education. Among the mapped conditions are: the ways we are governed, that is, the model of conduct guided by corporate means of action, professionalization, the systematization of education and the constitution of a field of knowledge.

Keywords: education; Business Administration course; power; knowledge; subjectivity.
\end{abstract}




\section{INTRODUÇÃO}

O estudo analisou de que modo essa formação foi possível e para isso foi necessário investigar os modos por meio dos quais os sujeitos administradores foram se constituindo historicamente (Foucault, 20Io), ou seja, analisou-se as condições de emergência da formação na área. Baseado nisso, foi preciso pensar junto com esse autor com base em três eixos.

1. Eixo das subjetividades: os modos pelos quais os alunos lidam com os códigos de conduta e se constituem como sujeitos administradores aqui se colocou em análise a produção de subjetividades no processo de formação.

2. Eixo dos poderes: as relações de poder que regulam as práticas na área caracterizaram-se os diferentes processos que levaram à administração a tornar-se um meio de vida.

3. Eixo dos saberes: a formação dos saberes que constituem a administração como uma doutrina - mapearam-se os processos pelos quais a administração foi tornando-se um campo de conhecimento e um curso de ensino superior.

Os materiais foram organizados em três eixos. Cada um exerceu uma atração em relação a determinados materiais, como se os materiais passassem a "girar" em torno dos eixos. O curso que serviu como disparador das análises foi o curso de administração da Universidade Federal do Espírito Santo (UFes).

\section{O TRAÇADO DA ROTA INVESTIGATIVA}

Como problematizar a emergência dos sujeitos administradores? Como pensar de que maneiras os administradores foram estabelecidos como objeto de conhecimento? Como escapar das dicotomias e dos princípios universais em funcionamento na área? Nesse estudo colocaram-se problemas para serem pensados, investigando-se como foram produzidas as formas em vigor no campo da formação em administração. "O" próprio campo da administração não seria justamente uma dessas formas, não seria algo produzido? 
Baseado no pensamento de Foucault (1979, 2003a, 2003b, 2008a, 2008b, 20Io) foram feitas modulações para poder pensar esta formação. Era preciso um ferramental que ajudasse a alinhavar as teorias com as análises das entrevistas, com a análise de documentos, com a legislação e os elementos históricos pertinentes ao estudo proposto.

"[...] o que encontramos frequentemente na pós-graduação é o trabalho inicial do orientando surgir, muitas vezes, cindido entre parte teórica e parte empírica, apresentadas em justaposição" (FERREIRA NETO, 2008, p. 542). No entanto, neste trabalho os eixos são produções teórico-empíricas.

A seleção dos materiais, os conceitos usados, o modo de construir a análise e o próprio texto e ocorreram orientados com base nos estudos de Foucault (2003a) sobre a relação entre códigos que regulam as maneiras de fazer (que prescrevem como educar os indivíduos) e uma produção de verdades, e saberes (que lhes servem como justificativa).

A pesquisa foi orientada por uma constituição de dados ao mesmo tempo em que pesquisadora e campo investigativo também eram constituídos, ou seja, ocorreu uma coemergência de pesquisador, campo e sujeitos. Os dados emergiram na relação da pesquisadora com a produção do próprio campo. O campo de investigação não estava dado, aguardando para ser investigado. Os dados também não estavam lá esperando para serem "descobertos". Pensar o problema de pesquisa proposto implicou na produção do próprio campo e na produção dos dados.

As leituras foram dispersas em diferentes áreas do conhecimento, como administração, educação, psicologia, filosofia e sociologia. Utilizaram-se autores não para justificar ou respaldar algo já dado, mas para ajudar a pensar um problema. Em relação às entrevistas, professores que lecionam no curso de administração da UFEs, alunos em vias de formação e administradores recém-egressos serviram como disparadores das análises. As entrevistas foram realizadas em diversos encontros, pois apenas uma entrevista mostrouse insuficiente, visto que a cada encontro questões surgiam e tornava-se urgente nova discussão. Todos os professores do departamento foram convidados a participar da pesquisa. Quatro professores se disponibilizaram, caracterizando um grupo formado por dois professores com praticamente 
20 anos de docência no curso e dois professores com menos de dez anos de docência no curso de administração da uFEs. O grupo de entrevistados, além dos quatro professores, também foi composto por dois alunos recémegressos e por seis alunos em vias de formação. Aqui, o critério foi o da acessibilidade.

Modos estabelecidos de pesquisar seriam incoerentes e não fariam jus a um estudo que não pretende encontrar ou produzir verdades. Então, preferiu-se forjar instrumentos que auxiliassem no processo de investigação.

Neste trabalho partiu-se do pressuposto de que a formação em administração não é algo já dado, não é uma categoria universal. Daí a importância de produzir uma análise que considere os processos que a compõem para além de categorias previamente aceitas. "É preciso também que nos inquietemos diante de certos recortes ou agrupamentos que já nos são familiares" (FOUCAULT, 2008a, p. 24). 


\section{EIXO DAS SUBJETIVIDADES}

Nesse eixo colocaram-se em análise os modos pelos quais os alunos lidam com os códigos de conduta e se constituem como sujeitos administradores. Portanto, se colocou em análise a produção de subjetividades no processo de formação em administração.

Os processos de formação produzem modos subjetivos. Por isso, é necessário analisar o que é produzido durante a graduação, quais esquemas comportamentais são recomendados, e como os estudantes estão se conduzindo frente ao que está, de certa maneira, estabelecido.

Há uma tendência na formação em administração que leva à aprendizagem de modelos, a seguir receitas, tentando replicá-los em outras realidades organizacionais e culturais, às vezes, muito diferentes daquelas nas quais foram concebidos. Modelos que imprimem formas que passam a ser consideradas formas corretas de ser administrador, como se houvesse um modo ideal de sê-lo. Contudo, no curso de administração analisado, foram percebidos também outros modos de relação sendo experimentados. Percebeu-se que os professores do curso de administração da UFES parecem não ignorar certos conteúdos. Mas, eles os colocam em análise e esse movimento permite a produção de modos menos padronizados de ser administrador.

"Do ponto de vista do ensino, me preocupo muito em fazer um papel que diria um pouco militante, que é não fazer o discurso convencional e hegemônico da administração, mas desconstruir todos os mitos da área na qual trabalhei. Na graduação, leciono disciplinas relacionadas à área [gestão de pessoas]” (PROFESSOR A).

"Ao falar de gestão ambiental você pode trazer todas as discussões do ponto de vista das organizações, das certificações, de como que isso funciona, o sistema integrado, e a discussão ética também pode vir toda voltada pra uma visão das organizações, pra falar de normas. E percebi que esses professores que davam essas disciplinas não estavam preocupados com nada disso. Estavam preocupados, realmente em discutir a questão ambiental e 
a questão ética. Isso foi passado em sala de aula e essa possibilidade não se pode perder" (ADMINISTRADOR B).

Os professores não subtraem ou desprezam determinados conteúdos, talvez considerados inadequados em sua percepção, visto que reproduzem certos modelos e mitos. Eles buscam colocá-los em análise para os alunos terem uma oportunidade de pensar de outros modos em relação a certas verdades que vem sendo produzidas da área.

Existem muitos currículos no ambiente escolar. No cotidiano do curso, alunos e professores criam currículo, estabelecendo outras práticas e outros conhecimentos para além das prescrições. Há uma dimensão processual do currículo, por meio da qual, experiências são ressignificadas "a partir das redes de poderes, saberes e fazeres" (ALVES, 2004, p. 4I).

As organizações, em sua maioria, pretendem contratar profissionais que estejam já habilitados para a prática, o que é difícil, visto que cada organização tem suas especificidades. Talvez, dessa exigência, venha parte da sensação de ansiedade dos alunos. Algo que os faz buscar aprender conteúdos que possam ser aplicados imediatamente a uma realidade organizacional, e também aprender modelos que precisariam ser seguidos.

"Sendo modismo ou não, acho que é válido porque gera discussão e toda discussão gera aprendizagem de alguma forma. Então, mesmo que seja modismo, a gente não tem certeza. Hoje, a gente estuda, a gente acha que pode considerar modismo, mas a gente não sabe se daqui a Io, 20 anos, isso realmente poder ter sido modismo ou não" (ALUNO A).

Como professores, não se pode ignorar aquilo que parece modismo ou, até mesmo, irrelevante para a formação, pois modismo é uma forma de funcionamento típico de uma época. No entanto, pode-se trabalhar tais conteúdos, a fim de mostrar suas fragilidades e as condições sociais e históricas que os produziram, analisando-os com os alunos, demonstrando que sendo produções, podem ser repensados e modificados.

"Acho que depois que o profissional se forma, quando ele vai pro mercado, parece que não é um profissional. Então o que acontece? Ele fica perdido. Ele tem uma formação que ele acha que com o conteúdo que recebe vai ser um profissional pronto. Só que isso não acontece. Aí, no caso, ele vai 
pro mercado. No mercado, ele procura no que se encaixar e ele não acha" (ALUNO B).

Os alunos em formação são governados por certas verdades que eles mesmos ajudam a reproduzir. Não se trata de coerção, mas de produção de subjetividades, de modos de ser e de se conduzir na vida. A relação entre governo e subjetividade, de acordo com Silva e Méllo (20II), é o resultado de um contínuo processo de produção dirigido à geração de modos de existências, que inclui modos de agir, de sentir e dizer. Com isso, concebese a ideia de sujeito administrador como algo que emerge como efeito de relações de poder e saber.

De acordo com López-Ruiz (2007), os indivíduos podem ser considerados trabalhadores-investidores, pois escolhem em qual empresa investir suas capacidades. Sendo assim, os alunos do curso de administração também podem ser considerados trabalhadores-investidores, pois, ainda que não trabalhem, já estão investindo esforços e tempo em organizações via estágios. Aqui se chama atenção para a responsabilidade dos futuros administradores desde sua formação num curso de ensino superior.

E a fim de analisar os modos pelos quais os alunos lidam com determinados códigos de conduta e se constituem como sujeitos administradores, buscouse alguns dos debates que os alunos vem travando com eles mesmos e com os professores em seus processos formativos.

Em muitas ocasiões em sala de aula, observou-se uma postura por parte dos alunos que não se sente convocada a entrar na discussão, que permanece passiva e não participa. A despeito das tentativas de promover discussões, muitas vezes, não há questionamentos em relação aos conteúdos nas aulas. Quando um aluno tem acesso à literatura gerencial, e em sala de aula coloca-se isso em análise, por vezes, é como se este já tivesse tomado essa produção como uma verdade, como uma regra a ser seguida. Um professor comenta sua impressão em relação à maioria dos alunos:

"Ele é muito calculista, de certa forma carreirista, vai mais rápido ao ponto, sonha menos. Ele já está de certa forma programado. Então, a educação tem menos efeito. Um professor não consegue, de certa forma, impor alguns conteúdos porque ele já vem com esses conteúdos da Internet, da televisão, 
dos jornais, da família, do capital cultural, que já traz das outras instituições. As escolas já estão implantando ensino político, filosófico, religioso, então aqueles que já vêm formados por essas instituições tem muito menos chances de serem uns alunos típicos que tínhamos na época de Sócrates, Aristóteles e de Platão que ainda se encantavam com novos modelos de vida. Hoje, já temos pessoas mais direcionadas pra aquilo que querem, ou seja, é a emancipação econômica" (PROFESSOR B).

As falas do aluno B e do professor B indicam parte do que acontece no cotidiano das aulas no curso de administração da UfEs. Entretanto, em muitas situações, é possível realizar debates que seguem em outra direção. Debates acalorados em que muitos alunos não titubeiam em discutir o que lhes for proposto. Muitos estão dispostos a entender o que os autores propõem e também a repensar o uso que é feito atualmente de seus pensamentos. Por isso, não se pode generalizar dizendo que produzir um debate em sala de aula sempre é algo difícil ou ainda que a maioria dos alunos simplesmente não queira discutir, sempre assumindo uma postura mais passiva diante dos conhecimentos.

Acredita-se que ao chegarem à universidade, mesmo com certa constituição subjetiva e profissional povoada de modelos do que é ser um administrador, ainda há espaço para serem produzidos novos modos de subjetivação.

Ainda assim, essa formação parece voltar-se mais para uma formação que enquadra e isso fez querer visualizar as forças que, conforme Chiappini (2008), fazem os administradores serem o que são, pois existem muitos aspectos que modelam uma forma administrador, modos de subjetivação que produzem um modo de ser administrador padronizado.

Os modos pelos quais o sujeito administrador é constituído durante a graduação referem-se à instituição de modelos e à incitação de práticas, prescrevendo e exaltando uma forma-administrador com uma identidade fixada. No entanto, subjetividade é processo, é modo de ser, de se conduzir, de sentir, de colocar-se no mundo. Processo que se cristaliza em certos momentos, mas permanece passível de modificação. 
Os processos de subjetivação, de acordo com Fonseca (2007), fazem das pessoas um sujeito preso a uma identidade que lhe é atribuída como própria. Tais processos podem ser compreendidos por meio da análise da maneira como os sujeitos se relacionam com certos conjuntos de regras em vigor num momento histórico, os modos pelos quais os sujeitos se percebem obrigados a cumpri-los e como se reconhecem ligados a eles.

Ainda que estejam mais estabilizadas, essas formas subjetivas são sistemas compostos por tensões, algo maleável e que não pode ser simplesmente circunscrito a uma identidade, pois esta ultrapassa a si mesma (COsta; FONSECA, 2008).

Neste estudo trata-se de sujeitos administradores, muito mais do que "o" sujeito administrador, tendo em vista que o sujeito não é uma substância, mas, sim, uma forma que não é sempre idêntica a si mesma (RAJCHMAN, 1989). Sendo assim, diferentes formas podem ser assumidas pelos administradores. Por isso, o processo de formação na graduação pode levar tanto a uma reprodução de formas predominantes quanto a uma produção de rupturas. Isso porque os alunos lidam de modos diferentes com as verdades produzidas na área e com os mecanismos de poder que agem junto a esses saberes.

A empresarização dos comportamentos em todos os níveis hierárquicos das organizações, segundo Ehrenberg (20I0), acaba fabricando uma mentalidade na qual cada um é impulsionado a governar a si mesmo. Esses modos de se relacionar com certos códigos estão produzindo formas subjetivas que acabam sendo vistas como algo ao qual não se pode escapar. Isso leva os alunos a governarem a si mesmos em um constante embate com forças econômicas que direcionam suas condutas.

Que processos estariam sendo vividos durante a formação dos administradores e que participam da sua constituição como profissionais da área? Os processos verificados no estudo foram a) a escolha do curso; b) o momento do trabalho de conclusão; c) o estágio supervisionado e d) a separação entre teoria e prática.

O que leva as pessoas a definirem a administração como a graduação a ser cursada? Uma pesquisa realizada pelo Conselho Federal de administração 
(CFA, 2006), demonstra que a afinidade está em segundo plano em relação às possibilidades de atuação profissional e que a escolha é influenciada pelo interesse na abertura do seu próprio negócio, mas principalmente pela formação considerada generalista.

Com isso, verifica-se que muitos profissionais podem não ter afinidade com a área na qual atua e isso é preocupante.

Outro processo vivido por aluno de administração é que nesse curso se faz necessário um Trabalho de Conclusão de Curso (TCC), uma disciplina de caráter obrigatório e profissionalizante.

"[...] quando tento orientar, são poucas as que conseguem crescer num processo de orientação. E elas já estão muito definidas, e muitas falam: não é isso que eu quero. Mudam de orientador e vão para outro semestre com outro orientador, isso é visível. Elas não aceitam, elas fogem de um conhecimento que vai colocá-las em questionamento, em parafusos. Elas não aceitam, por isso que abandonam" (PROFESSOR B).

A experiência do trabalho de conclusão de curso é uma das práticas vivenciadas pelos alunos durante o processo de formação. Essa prática é atravessada por regras de conduta, pela mentalidade empresarial, e participa do processo de produção de modos de ser. O que as experiências de orientação vêm mostrando?

Dependendo das práticas (prática, do grego praktike, significa uso, experiência, exercício), nas quais estão envolvidos (estágio, emprego, negócios da família), os alunos são subjetivados de modos diferentes, isto é, alguns estarão mais enquanto outros estarão menos governados por certas verdades. No governo de si mesmo, Foucault (2008a; 2008b, 2010), alguns não suportarão colocar em análise algumas verdades que lhe são preciosas e procurarão outros professores para o processo de orientação. Outros estabelecerão uma relação mais indagadora e colocarão em análise alguma questão que lhes despertou a atenção durante o curso.

Outro aspecto a ser considerado é que os modos como tais ideias podem ser trabalhadas com os alunos podem levar a um interesse, mas também a um distanciamento, a uma espécie de aversão a determinados assuntos e até a determinadas disciplinas da matriz curricular. Observou-se com 
base nas interações com alunos nas aulas e nas entrevistas que a crítica ao que seria reacionário, realizada por alguns professores, pode ser tão conservadora quanto aquilo a que faz oposição e isso assusta os alunos. Talvez seja possível conseguir mais alunos interessados em temas de TCCs menos reacionários, se ao longo do curso a eles forem apresentados modos menos impositivos e radicais de repensar sua área de atuação.

Percebeu-se que os processos de subjetivação também podem produzir alunos que ao chegarem no momento do TCC, encontram-se mais permeáveis a novos pensamentos, que estão mais receptivos para colocar em análise as verdades produzidas na área. Também se observou alunos mais receptivos a outros modos de administrar para além dos modelos consagrados.

Outro ponto é que o tema para o trabalho de conclusão de curso, de acordo com o projeto pedagógico, precisa ser considerado relevante. Mas, precisa ser relevante para quem? Acredita-se que para o professor e para o aluno. No entanto, como as escolhas dos alunos, muitas vezes, ocorrem prioritariamente em função da empregabilidade, há uma busca pela aprendizagem de saberes mais específicos e que possam ser imediatamente aplicados nas organizações, o que pode ir de encontro aos interesses de pesquisa dos professores. Há que se buscar equilíbrio em relação a isso, para que ambas as partes trabalhem com temas que considerem relevantes.

Ocorre que os conhecimentos técnicos podem tornar-se rapidamente desatualizados, sendo mais relevantes a capacidade de adaptação ao ambiente organizacional e a capacidade para aprender do que propriamente ter conhecimentos técnicos. Há uma descartabilidade dos saberes que são aplicados nas organizações, visto que as demandas estão em constante modificação (sCHUCH JR., 1978).

Durante o processo de formação, existem algumas possibilidades dos alunos vivenciarem o cotidiano organizacional. Duas delas seriam o estágio obrigatório, também chamado de estágio supervisionado, e também o estágio não obrigatório. Este último não soma créditos para o aluno, nem tem um acompanhamento mais efetivo por parte do curso e da própria universidade.

De acordo com o Projeto Pedagógico do Curso, "o estágio supervisionado deve ser um mecanismo que possibilite a oportunidade de vivenciar 
aspectos práticos relevantes à formação profissional, além da contribuição obtida em sala de aula” (UNIVERSIDADE FEDERAL DO ESPÍRITO SANTO, 20IO, p.34). Aparentemente, há um entendimento produzido ao longo dos anos em relação ao estágio supervisionado de que ele serviria somente para cumprir créditos, com a mera entrega de um relatório.

Nicolini (2003) chama atenção para este aspecto, ao falar que a última etapa da linha de produção de administradores seria o estágio supervisionado. $\mathrm{O}$ autor percebe que o estágio supervisionado não atende a critérios mínimos de supervisão e a possibilidade dos alunos vivenciarem situações nas organizações acaba tendendo à mera geração de relatórios.

O estágio supervisionado seria uma importante vivência para os alunos, mas, que muitas vezes pode não ser devidamente aproveitada. Seja pela preconcepção de que o estágio somente serve para somar créditos, seja porque não há uma efetiva supervisão por parte dos professores em uma clara insuficiência de carga horária para tal atividade, seja porque as organizações contratam alunos de administração para realizarem aquilo que estagiários de ensino médio ou técnico poderiam realizar.

Esse tipo de estágio, que não proporciona uma oportunidade de experimentar os saberes da área, que não remunera adequadamente, contribui, de fato, para o processo formativo desses alunos? Contribui, em parte, pois os alunos já começam a experimentar o ambiente organizacional e a estabelecer relações com pessoas, trabalho, regras e situações. Mas, em relação à utilização dos saberes da administração em situações concretas no ambiente organizacional, não se pode afirmar que contribua. Depende da organização, depende do gestor que acompanha (quando acompanha) o estagiário, e do grau de autonomia que haverá no ambiente organizacional para que ele desenvolva suas atividades e experimente na prática os conhecimentos que vem aprendendo no curso.

Observou-se também uma espécie de clivagem entre teoria e prática. Tal clivagem gera descontentamento e angústia entre os alunos, e isso é notório nas discussões durante as aulas e na fala a seguir:

"A prática que falta no curso de administração é a prática para o exercício profissional. Isto porque o mercado quer profissionais com experiência em 
determinada área e isso, no meu ponto de vista, é uma crueldade, porque o curso não oferece essa experiência e por isso concordo com a ideia de que o mercado e o curso em administração trilham por caminhos opostos, pois o mercado exige que o profissional tenha experiência, e as instituições de ensino oferecem apenas um embasamento teórico. Aí quando chegam ao mercado se sentem despreparados porque não têm a experiência exigida" (ALUNO B).

A clivagem entre teoria e prática parece ser efeito de um modo de conceber o processo de formação, no qual os alunos precisam de um arcabouço teórico para embasar as suas práticas. A questão colocada é a da aplicabilidade. Como se o que não é imediatamente aplicável fosse pejorativamente teórico. Mas, o inverso também ocorre, quando aquilo que é mais aplicável é desdenhado por professores do curso. No entanto, ambas são necessárias a essa formação.

Os alunos são constituídos como administradores nas aulas, na experiência dos estágios obrigatórios e estágios não obrigatórios. Por meio dos estágios já vão experimentando o cotidiano organizacional e os modos de funcionamento ali em ação. As experiências vividas nas aulas, trabalhos em grupo, atuação em projetos de pesquisa, tudo isso estabelece relações entre campos de saber, tipos de normatividade e produção de subjetividade. De acordo com Foucault (2003b), nesses processos de experimentação, modos de subjetivação estão em funcionamento, sendo a sujeição um de seus efeitos possíveis, ou seja, a formação de sujeitos profissionais da administração.

Neste eixo foi analisada a produção de subjetividades no processo de formação em administração e para isso foram considerados os múltiplos vetores que a constituem tal formação. 


\section{EIXO DOS PODERES}

Neste eixo foram analisadas as relações de poder que regulam as práticas na área e os diferentes processos que levaram à administração a tornar-se um meio de vida, isto é, uma profissão. Daí a relevância em caracterizar os processos de profissionalização da área.

A administração como meio de vida foi tornando-se possível com o advento da grande empresa, em que cada um dos importantes processos passou a ser administrado por um departamento, todos sendo supervisionados e coordenados por um escritório central. De acordo com Chandler (I998), o escritório central coordenava, monitorava e avaliava o desempenho das divisões, planejava o crescimento organizacional e alocava os recursos necessários à execução do que fora planejado. A moderna empresa era administrada por uma hierarquia de executivos assalariados, contratados em regime de tempo integral. A hierarquia de gestores assalariados era composta de uma primeira e segunda linhas e era considerada uma classe inteiramente nova de homens de negócio.

No Brasil, as décadas finais do século xıx foram marcadas pela expansão de pequenos núcleos urbanos e cidades, que eram povoados por fábricas e conjuntos industriais que iam modificando a paisagem e imprimindo-lhes um novo ritmo de atividades. Novas formas de vida que ainda conviviam com o mundo agrário. O crescimento populacional no Brasil, unido ao processo de urbanização, também pode ser um indício da busca por trabalho e educação. Para Bertero (2006), as populações urbanas passavam a demandar cada vez mais educação, e as camadas médias, um acesso ao ensino superior, visto que percebiam a educação como relevante no processo de ascensão social.

Os processos de industrialização e urbanização coexistiam. Se antes o trabalhador detinha um controle sobre o processo e as condições de trabalho, com a mecanização da produção esse controle acaba escapando de suas mãos. Diferente da parcelização das tarefas, o que se percebe aqui é um processo de dissociação entre os atos de conceber e de executar a atividade, uma dissociação entre a concepção e a execução do trabalho. 
A profissionalização é uma tentativa de demarcação de um território de atuação. Nesse processo, os administradores tanto podem reafirmar uma lógica que defende uma hierarquia e modos de gestão verticalizados, quanto podem produzir outros modos de relações e de gestão, nos quais não há uma separação entre aqueles que pensam (planejam, organizam, dirigem e controlam) e aqueles que somente executam.

"A gente tem mania de pensar sempre nas grandes empresas. A gente nunca considera que tem possibilidades nas pequenas. Quando falo do ponto de vista das grandes, falo da Vale, Fibria, Petrobras, empresas que tem projetos voltados para captação, projetos de treinamento, projetos que são voltados pra complementar essa formação que fica deficiente na graduação dos cursos. Não sei se eu posso usar o termo, mas as grandes empresas é um "fetiche" pros estudantes. Falta apenas despertar essas oportunidades nas pequenas e médias. Lógico que a demanda vai ser muito maior pelo conhecimento generalista. O administrador numa grande empresa vai pegar um recorte do processo, enquanto um administrador numa média ou pequena vai ter que dispor de recursos para ser de RH, de produção." (ADMINISTRADOR A).

Se antes, nos Estados Unidos, muitos alunos de graduação ansiavam ingressar em grandes empresas somente para aprender todos os truques e depois abrir seu próprio negócio, na década de 1960, isso já não ocorria com tanta intensidade. Os alunos acreditavam que uma vez estabelecido um laço entre eles e uma grande companhia não mudariam para uma menor nem passariam a uma maior, pois a relação seria algo duradouro. A maioria dos alunos se assustava com a ideia de ser empresário devido aos riscos - embora argumentassem que não se tratava de temer riscos. Eles simplesmente buscavam o melhor lugar para afrontar tais riscos, alegando que a empresa pequena não crescia devido a um nepotismo, sendo escassa de perspectivas.

Diferente da figura do empreendedor que caracterizava a sociedade do século xix e início do século xx (empreendiam negócios), aqueles que se formavam na década de 1950 nos euA e que viriam a serem gestores profissionais eram jovens que saíam das universidades e almejavam 
entrar em uma empresa. Desse modo, ocorre um deslocamento dos empreendedores para os empregados assalariados (BOLTANSKI; CHIAPELLO, 2009).

López-Ruiz (2007) faz uma análise sobre o deslocamento que ocorre entre essa figura do empreendedor e a do empregado dependente, que seriam os funcionários, os executivos e aqueles subordinados que preferem delegar a uma organização a definição de objetivos para poderem se concentrar nos meios para alcançá-los. Aqueles que almejam trabalhar para outros acreditam que assim conseguirão realizar suas aspirações econômicas e procuram uma espécie de sensação de segurança por estarem ligados a uma empresa de grande porte.

Contudo, outros processos também contribuíram para a profissionalização da área em questão. Eapesar de disseminada a ideia de que os administradores foram necessários baseada nas demandas da industrialização, que o desenvolvimento econômico baseado no modelo da grande empresa levou à necessidade de mão de obra com nível superior (COVRE, I98I), outros processos igualmente levaram a uma profissionalização da área. Ao mesmo tempo, o ensino vinculado à administração foi tornando-se cada vez mais necessário.

O Estado precisava manter uma burocracia militar para a defesa do território e controle interno da burocracia civil para as questões fiscais, justiça e controle das relações externas. Os filhos de trabalhadores das cidades e descendentes de colonos das fazendas passaram a tentar se afastar dos trabalhos manuais por meio de atividades subordinadas em escritórios, lojas e repartições. Durante o processo de ampliação da burocracia pública e privada, os latifundiários queriam ter filhos formados para o desempenho de atividades políticas e para a ampliação do prestígio familiar, e os colonos e os trabalhadores urbanos desejavam a escolarização dos filhos visando ao ingresso destes em atividades burocráticas (MICELI, 1979).

Neste eixo visualizaram-se três processos que contribuíram para a emergência da administração como uma profissão: a necessidade de trabalho, a necessidade de burocratas e a necessidade de mão de obra para indústria. Houve uma necessidade de trabalho assalariado nas cidades por 
parte de uma população crescente, uma necessidade de burocratas para o aparelhamento estatal no Brasil e uma necessidade de administradores para o gerenciamento em organizações privadas. 


\section{EIXO DOS SABERES}

Como foi o processo de formação dos saberes que acabaram constituindo a administração como uma doutrina? Neste eixo são apresentados alguns pontos nos quais um campo de conhecimento - a administração - vai sendo produzido.

Toda disciplina tem o seu discurso. Uma disciplina veicula um discurso da regra natural, da norma, definindo um código que não é exatamente o da lei, mas o da normalização (FOUCAULT, I979).

"A administração não está somente como curso de Administração. Estou falando de um processo de gestão que está na cabeça do médico, do advogado, do engenheiro, porque todos esses profissionais serão gestores do sistema” (PROFESSOR B).

Há um jogo de relações de poder que tenta imprimir uma demarcação desse campo, como em outras profissões, mas que esbarra em uma mentalidade empresarial e na disseminação dos conhecimentos de gestão que são produzidos e cosumidos para além da formação em administração.

Com a administração, nos aproximamos de um polo no qual os princípios de gestão se explicitam à medida que nos afastamos da própria atividade. Há dissociação entre atividade e gestão da atividade. Usualmente - e compreendese aqui o nosso desacordo - é unicamente quando há essa dissociação que se fala, profissionalmente de gestão e de gestores (schwARTZ, 2004, p.3I).

Com isso, vai sendo constituído um campo de conhecimento. Os saberes que eram consolidados baseados em experimentos nas organizações pretendiam encontrar princípios que tornasse possível a qualquer um, a melhor condução das atividades e negócios. Havia uma busca pela disseminação desses saberes.

Tais noções foram e são perpetuadas por meio do pensamento dos autores considerados fundamentais no ensino da área - Taylor, Ford e Fayol, dentre outros. Contudo, essas noções podem ser colocadas em análise na disseminação dos conteúdos. Com base nisso, colocam-se em evidência as tentativas de delimitação de um território que seria habitado somente por aqueles que têm acesso a determinados saberes e a produção de um determinado campo de conhecimento. 
"Está claro, então, na maioria dos casos, que um tipo de homem é necessário para planejar e outro para executar" (TAYLOR, 1969, p.37). Ele tenta comprovar essa ideia utilizando como exemplo a aplicação do sistema de administração científica ao serviço de manejar lingotes de ferro, no qual seleciona como operário padrão um homem que fosse capaz de trabalhar durante anos e feliz sem sentir os prejuízos da fadiga, no momento que fosse treinado para tal. Conforme Taylor (1969. p.56):

Um dos primeiros requisitos para um indivíduo que queira carregar lingotes como ocupação regular é ser tão estúpido e fleumático que mais se assemelhe em sua constituição mental a um boi. Um homem de reações vivas e inteligentes é, por isso mesmo, inteiramente impróprio para tarefa tão monótona.

Daí a expressão "homem do tipo bovino". Talvez aqui esteja um dos indícios do que viria a ser a atual valorização de um elitismo intelectual da administração e, como lembra Faria (2006), um reforço da ordem capitalista sob a proteção de relações autoritárias.

O processo de separação entre a concepção e a execução viria com a intenção de facilitar o trabalho e melhorar os resultados, , para que fosse possível uma condução cada vez mais racional das organizações. Que tipo de racionalidade é esta? Uma racionalidade que prima por uma adaptação dos meios aos fins, uma racionalidade instrumental.

Ford (1995, p.I48), na década de 1920, tenta explicar o porquê dos trabalhadores desempenharem ou não certas funções:

Necessariamente, o trabalho de muitos homens tem de ser pura repetição de movimentos, pois de outro modo não se pode conseguir sem fadiga a rapidez da manufatura que faz descer os preços e possibilita os altos salários. Algumas das nossas operações são excessivamente monótonas, mas também são monótonos muitos cérebros; numerosos homens querem ganhar a vida sem ter que pensar - e para estes a tarefa unicamente de músculo é a boa. [...] homens que no trabalho de repetição se revelam de mentalidade ativa não permanecem nele muito tempo.

Aqui, vemos novamente uma produção de certas noções que procuram demarcar um território entre aqueles que sabem e aqueles que não sabem. 
Isso vai sendo reproduzido e institucionalizado, produzindo verdades, sujeitos e modos de funcionamento que, muitas vezes, ainda são perpetuados em nossos dias.

Em meados do século xx, Fayol (1970, p. 26) já defendia a existência de uma "doutrina consagrada, isto é, um conjunto de princípios, de regras, de métodos, de procedimentos postos à prova e controlados pela experiência geral”. Para ele, somente assim seria possível o ensino administrativo. A busca por uma doutrina consagrada que tornasse o ensino administrativo factível estava atrelada à afirmação da administração como um campo de conhecimento.

Cabe ressaltar que se trata de uma área que se encontra na categoria das ciências sociais e aplicadas da CAPES (Coordenação de Aperfeiçoamento de Pessoal de Nível Superior). Em relação à importância das ciências sociais na formação em administração, Bertero (2006) explica que nos cursos iniciais essa formação foi orientada pelo embasamento nas ciências sociais e pela ênfase na administração como profissão modernizadora. Pensava-se que as ciências sociais auxiliariam no processo no qual nosso país passaria ao nível de outros países.

As ciências sociais no país tiveram influência da sociologia norteamericana, voltada para conhecimentos positivos, fundados na pesquisa empírica e que permitissem aplicações sociais imediatas. Mudanças seriam realizadas sob o comando de cientistas e industriais, mas em um processo em que instituições garantiriam o funcionamento da sociedade (família, direito, propriedade, religião), produzindo um consenso e promovendo o progresso, determinando suas leis e seu percurso (FERREIRA, 20IO).

O positivismo é uma maneira de pensar baseada na suposição de que é possível observar a vida social e reunir conhecimentos confiáveis sobre como ela funciona. Ao estudar organizações, ainda percebe-se sua presença sempre que se procura investigar objetos para achar a verdade e suas leis de funcionamento.

Nesse sentido, o processo de formação em administração é ainda muito pautado nos conhecimentos estrangeiros, privilegiando casos, teorias e autores norte-americanos. A razão para tal preferência está mais ligada 
a uma necessidade de referir-se a um conhecimento já legitimado no circuito internacional, do que propriamente, à sua capacidade de explicar os problemas investigados. A literatura nacional não é considerada inferior em qualidade, carecendo apenas de prestígio e alcance internacional (RODRIGUES; CARRIERI, 20OI).

A produção brasileira, acumulada ao longo de mais de 30 anos, demonstra que ainda são consumidas, repetidas e divulgadas ideias predominantemente norte-americanas. Ademais, os assuntos indicam que os estudos brasileiros seguem tendências dos países dos quais as ideias são oriundas, o que levaria à presença dos sucessivos modismos na área (BERTERO; KEINERT, I994).

Ainda assim, esse campo que procura se constituir em relação aos conhecimentos de administração, como uma espécie de doutrina, não é um universal (FOUCAULT, 2008B). São mais conjuntos de práticas que vão produzindo relações de poder e certos saberes que vão estabelecendo certas verdades. Observa-se que os saberes da área estão organizados em escolas, movimentos e teorias, que procuram demonstrar uma espécie de "evolução" ou "progresso" em relação aos próprios conhecimentos da área. Porém, existem outras visões acerca do assunto:

"Não concordo que o conhecimento da administração possa ser, de certa forma, classificado em escolas, enfoques ou abordagens porque por enquanto só conhecemos uma escola, que é uma escola capitalista, produtivista, instrumentalista e exploratória tanto dos seres vivos, quanto da natureza, dos recursos naturais, dos recursos humanos e dos recursos animais. Os conteúdos quase que universais não saem desse dilema de estar sempre comprometido com maior produtividade, capacidade de controle, de quem queira ou do que queira fugir desse controle. A administração nunca fugiu do paradigma clássico, aliás, só ampliou o paradigma clássico para o sistema global, ou seja, saiu da fabriqueta da unidade isolada e partiu para o sistema global" (PROFESSOR B).

Algumas condições que levaram ao estabelecimento de concepções e práticas organizacionais tornaram possível conceber a administração como uma doutrina, como um campo de conhecimento possível. Os saberes por ela disseminados foram constituídos com base em aspectos anteriores aos 
processos de industrialização e burocratização, que foram ganhando força não só com base nos modos de funcionamento das organizações militares e da igreja, mas também com o pensamento de filósofos, os estudos de cientistas sociais, engenheiros e tantos outros que deixaram suas marcas.

Para além do discurso vigente, foi possível traçar um panorama acerca da emergência da administração como um curso de ensino superior. Conforme dados divulgados pelo INEP 20II (Instituto Nacional de Estudos e Pesquisas Educacionais Anísio Teixeira) referente ao censo da educação superior, em 2009 já somavam I,I milhão os alunos matriculados nos cursos de administração. Como um curso chega a ser alvo de tanta procura?

Antes de emergir como um curso superior, outros cursos superiores estavam funcionando como suprimento de mão de obra para as demandas da sociedade. Ocorre que alguns dos cursos que supriam mão de obra de nível superior, começaram a passar por um processo de desvalorização - o que também pode ter contribuído para a emergência do curso de administração.

Os saberes administrativos podem ter tornado-se mais atrativos, em parte, devido aos processos de desvalorização de alguns cursos. Alguns cursos deixaram de ser tão atrativos no momento em que passaram a formar muitos indivíduos e, com isso, a reduzir os ganhos salariais devido à grande oferta de profissionais.

Aqueles que possuíam melhores relações sociais e oportunidades de acesso ao nível superior, começavam a lidar com uma desvalorização dos diplomas universitários na década de 1930. Tal desvalorização ocorria principalmente, segundo Miceli (1979), nas áreas das profissões liberais, nas quais a concorrência entre os profissionais se acirrava. A concorrência era movida por uma nova geração de especialistas em áreas em expansão, como educadores, economistas, cientistas sociais, psicólogos que passam a disputar as mesmas vagas.

Atualmente, o curso de administração assume uma posição estratégica na sociedade, não porque estaria incumbido primeiramente, de formar pessoas para auxiliar na condução dos mais variados tipos de organizações (objetivo explicitado), mas, sobretudo, porque acaba servindo como uma 
possibilidade para milhares de pessoas fazerem um curso superior. Ainda que não venham a atuar como tal ou ainda que tenham apenas relativa afinidade com as atividades da área, muitos o fazem porque acreditam ser um curso abrangente. Acreditam que poderão utilizar os conhecimentos em qualquer atividade ou área, facilitando a sua entrada e permanência nas organizações.

Entretanto, como argumenta o professor A, para ser um executivo bem sucedido, a formação precisa ser consistente, isto é, precisa ser uma formação embasada no conhecimento dos saberes da área, articulada com outros saberes necessários ao trabalho de alguém que lida com pessoas e organizações de diversos países e embasada na experiência de trabalho. O que talvez signifique que a maioria dos altos executivos não sejam tão jovens. Daí ser necessário construir uma história profissional, e isso pode levar tempo - o que parece ir contra a rapidez tão perseguida hoje em dia.

Portanto, pode-se dizer que os saberes da área foram tornando-se cada vez mais necessários e o curso passou a ser consideradocomo um caminho possível para a formação no ensino superior no Brasil. Interessante observar que esses saberes antes eram aprendidos em diferentes níveis de ensino: no ensino de ofícios, na escola industrial primária, na escola técnica e no ensino comercial.

O ensino comercial foi iniciado em I808, no Rio de Janeiro, com a cadeira e aula pública de Ciência Econômica, cuja regência foi destinada ao Visconde de Cairu. Em 1846, o Governo Imperial regulamentou as Aulas de Comércio, estabelecendo disciplinas de caráter prático voltadas às necessidades do comércio e dos negócios bancários $\mathrm{O}$ ensino comercial contribuiu para o estabelecimento dos cursos superiores de Economia, Administração e Contabilidade no Brasil, sendo que tais cursos foram um desdobramento do ensino comercial. A distinção entre eles pode ser considerada recente e muitas das funções exercidas por esses profissionais se sobrepõem no cotidiano de trabalho (SAES; CYTRYNOWICZ, 200I).

Os saberes da administração circulavam em diferentes níveis educacionais em um processo de expansão que abrangia, desde aqueles considerados menos favorecidos até os que buscavam habilitação para trabalhar em indústrias, em atividades comerciais ou como burocratas. 
A ESAN (Escola Superior de Administração de Negócios) foi fundada pelo padre jesuíta Roberto Sabóia de Medeiros em 194I, em São Paulo, durante o período da ditadura de Getúlio Vargas (1930-1945), seguindo ideais educacionais da Companhia de Jesus (CRA SP- MS, I99I). Esse fato é pouco divulgado e, segundo Bertero (2006) e Vizeu (2008), talvez tenha sido ofuscado devido à criação da EAESP, da FGV, e do curso de administração da USP, que ocorreu alguns anos depois. Somente em 1946, foi criada a Faculdade de Economia e Administração (FEA), da Universidade de São Paulo, cujo objetivo era a formação de funcionários para a de Administração pública e privada.

Somente a partir de 1968, com a Reforma Universitária, ocorreu a expansão dos cursos de administração. Ou seja, os saberes da área foram constituídos de acordo com a necessidade de organizar e colocar em funcionamento determinadas atividades, sejam públicas ou privadas. Sua sistematização é recente, assim como a escolarização e a profissionalização a eles vinculados.

"Eu me preocupo com a formação, que ele saia um cidadão crítico e capaz de refletir sobre a sociedade e tento fazer com que ele saia daqui uma pessoa mais justa, com ética, que não seja levar vantagem em tudo, ou seja, tento fazer com que ele saia um cidadão que possa contribuir de alguma forma para sociedade" (PROFESSOR C).

O modo de funcionamento do curso analisado procura produzir, ao contrário de um aluno passivo, um aluno que pense sobre o que está sendo dito, que busque um entendimento de como fazer com que conteúdos, quase sempre um tanto abstratos, sejam repensados diante da prática organizacional. Contudo, há uma forte relação da formação com a necessidade de emprego e isso faz com que alunos, realizem suas escolhas, não considerando a rede complexa que produz certo estado de coisas.

Os cursos de administração formam muitos profissionais. Ainda assim, a universidade vem gerando descontentamento em muitas organizações, pois estas não são totalmente atendidas em suas demandas específicas. Ao mesmo tempo, há um descontentamento por parte daqueles que deixam a universidade, já que não se sentem preparados para atuarem nas organizações. 
Por meio da análise das entrevistas, assim como da análise de documentos e de aspectos históricos relativos à área, juntamente com o aporte teórico, foi possível analisar a formação e a constituição do sujeito administrador como algo que foi sendo possível graças à convergência de diversos aspectos, ou seja, é uma produção social. Foram analisados os modos pelos quais os alunos lidam com os códigos de conduta e se constituem como sujeitos administradores, isto é, a produção de subjetividades no processo de formação. Em seguida, foram analisadas as relações de poder que regulam as práticas na área, com a caracterização dos diferentes processos que levaram à administração a tornar-se uma profissão. Por último, foi analisada a formação dos saberes que foram constituindo a administração como um campo de conhecimento e um curso de ensino superior. 


\section{CONSIDERAÇÕES FINAIS}

Não houve a pretensão de produzir uma nova verdade sobre a formação em administração, mas sim, mapear as condições de emergência desses profissionais e de sua formação. O estudo permite afirmar que há uma tendência na formação em administração que leva à aprendizagem de modelos, tentando replicá-los em outros ambientes organizacionais e culturais, que podem ser bastante diversos daqueles nos quais foram concebidos. Ao mesmo tempo, essa formação também se dá via indagações sobre modos idealizados. Ambas as práticas são produzidas no curso de graduação da UFEs.

Há uma ansiedade observada nos alunos referente ao futuro profissional e que é produzida na relação com as organizações, visto que estas, muitas vezes, pretendem contratar profissionais que já estejam habilitados para uma aplicação imediata de conhecimentos.

O curso de administração, campo empírico desta pesquisa, apresentou práticas de ensino que desafiam o hegemônico na área e um desvio de práticas que privilegiam uma "transmissão" de conteúdos. Existe um esforço por colocar em análise determinados conteúdos, determinadas práticas dos profissionais de administração, sem renegar ou omitir saberes. O esforço é por repensá-los, analisando os usos que são feitos deles e como foram concebidos, muito mais do que o ensino da aplicação de tecnologias de gestão.

Há uma aprendizagem de tecnologias, mas não exatamente uma aprendizagem da sua aplicação, pois o uso será vivenciado no cotidiano de trabalho e, em alguns casos, nos estágios. Com isso, existe um descontentamento dos alunos em relação a uma falta de experiências. Diferente de outros cursos superiores, aqui o TCC é muito valorizado no processo formativo, enquanto o estágio ainda carece de acompanhamento efetivo e de valorização. É preciso analisar como o estágio pode contribuir para essa formação.

Outro modo de constituição dos futuros administradores se dá por meio das atividades de pesquisa. Entretanto, tal prática, no curso analisado, está 
sendo fortalecida e enquanto isso, estágios e subempregos remunerados têm a preferência dos alunos.

Ao mapear a emergência da formação em administração foi possível verificar a constituição do sujeito administrador como alguém que passa a exercer uma profissão que antes não existia (diversos processos de profissionalização).

Dentre as condições de existência dessa profissão e dessa formação estão os modos pelos quais os indivíduos são governados atualmente, ou seja, há uma mentalidade empresarial que governa a todos. Além disso, é uma formação ainda muito pautada em conhecimentos estrangeiros. Uma influência oriunda do deslumbramento por um tipo de desenvolvimento e modo de vida que passaram a servir como referência, mas que atualmente, mostram ao mundo sua fragilidade.

No ensino da área, saberes mais aplicáveis e instrumentalizados, muitas vezes, são menosprezados em detrimento de saberes mais conceituais. Em outros casos, acadêmicos da área podem não tratar de conhecimentos diretamente aplicáveis. Porém, tais conhecimentos também são necessários aos futuros administradores. Como produzir uma formação que não privilegie a aplicação "ou" o conceito?

As condições de existência dos administradores e de sua formação apontam para uma tentativa de demarcação de um território para atuação profissional e de demarcação como ciência. No entanto, tais saberes atualmente são buscados por diversos profissionais que também tem suas condutas governadas pela mentalidade empresarial, são empresários de si mesmos.

Administração e seus saberes não são verdades estabelecidas e imutáveis, são muito mais práticas que vão produzindo e estabelecendo certas concepções como verdadeiras. Ao compreender a administração como processo, é possível perceber que administradores e organizações são produzidas ao mesmo tempo.

Também é importante considerar que nem todos os administradores agem e pensam da mesma maneira. Se subjetividade é processo, é modo de se conduzir e de colocar-se no mundo, algo que assume formas em certos 
momentos, mas que sempre é passível de modificação, então, o processo de formação pode levar tanto à reprodução de formas predominantes quanto à produção de rupturas com tais formas. O processo de formação engendra múltiplos sujeitos administradores. Formas, que por serem provisórias, podem ser reconfiguradas, escapando, mesmo que de forma ínfima, de alguns modelos vigentes, sendo profissionais mais atentos à época presente.

Portanto, para pensar como os sujeitos administradores e sua formação foram estabelecidos historicamente, foi preciso mapear suas condições de emergência. Uma constituição possível por meio de verdades produzidas e que proliferaram, ao mesmo tempo, em que produziam o próprio campo de conhecimento, a necessidade de profissionalização e a necessidade da sistematização do ensino. 


\section{REFERÊNCIAS}

ALVES, N. (Org.). Criar currículo no cotidiano. 2.ed. São Paulo: Cortez, 2004.

BERTERO, C. O. Ensino e pesquisa em administração. São Paulo: Thomson Learning, 2006. (Coleção Debates em Administração).

; KEINERT, T. M. M. A evolução da análise organizacional no Brasil (1961-93).

Revista de Administração de Empresas, v. 34, n. 3, p.81-90, 1994.

BOLTANSKI, L.; CHIAPELLO, È. O novo espirito do capitalismo. São Paulo: Martins Fontes, 2009.

CHANDLER, A. D. Os primórdios da 'grande empresa' na indústria norte-americana. In: MCCRAW, T. K. (Org.). Alfred Chandler: ensaios para uma teoria histórica da grande empresa. Rio de Janeiro: FGV, 1998a, p. 35-66.

CHIAPPINI, P. Cartografias da empresa: práticas empresariais e produção de subjetividade. 2008. Dissertação (Programa de Pós-Graduação em Psicologia Social) Universidade do Estado do Rio de Janeiro, Rio de Janeiro, 2008.

CONSELHO FEDERAL DE ADMINISTRAÇÃO. Pesquisa Nacional Perfil, formação, atuação e oportunidade de trabalho do administrador. Brasília: CFA, 2006.

CONSELHO REGIONAL DE ADMINISTRAÇÃO: São Paulo - Mato Grosso do Sul. Administrador de empresa: cinquentenário do ensino no Brasil. Aconteceu. Informe especial. Setembro, 1991.

COSTA, L. A.; FONSECA, T. M. G. Da diversidade: uma definição do conceito de subjetividade. Interamerican Journal of Psychology, v. 42, n. 3, p. 513-519, 2008.

COVRE, M. L. M. A formação e a ideologia do administrador de empresas. São Paulo: Cortez, 1981.

EHRENBERG, A. O culto da performance: da aventura empreendedora à depressão nervosa. Aparecida, São Paulo: Ideias \& Letras, 2010.

FERREIRA, D. Manual de sociologia: dos clássicos à sociedade de informação. 2.ed. São Paulo: Atlas, 2010.

FERREIRA NETO, J. L. A experiência da pesquisa e da orientação: uma análise genealógica. Revista de Psicologia, v. 20, n. 2, p. 553-546, 2008.

FONSECA, M. A. Michel Foucault e a constituição do sujeito. São Paulo: EDUC, 2007.

FOUCAULT, M. Microfisica do poder. 26.ed. Rio de Janeiro: Edições Graal, 1979.

O uso dos prazeres e as técnicas de si. In: MOTTA, M. B. da. Ditos \& Escritos V.

Ética, sexualidade e política. Rio de Janeiro: Forense Universitária, 2003a.

Conversação com Michel Foucault. In: MOTTA, M. B. da. Ditos \& Escritos IV.

Estratégia, poder-saber. Rio de Janeiro: Forense Universitária, 2003b.

A arqueologia do saber. 7.ed. Rio de Janeiro: Forense Universitária, 2008a. 
O Nascimento da Biopolitica. São Paulo: Martins Fontes, 2008b.

. A hermenêutica do sujeito. 3.ed. São Paulo: WMF Martins Fontes, 2010.

INEP. Censo da educação superior. Brasil tem hoje 5,9 milhões universitários, indica o censo. Disponível em: http://www.inep.gov.br/superior/censosuperior/. Acesso em: 19/08/2011.

LÓPEZ-RUIZ, O. J. Os executivos das transnacionais e o espirito do capitalismo: capital humano e empreendedorismo como valores sociais. Rio de Janeiro: Azougue Editorial, 2007.

MICELI, S. Intelectuais e classe dirigente no Brasil (1920-1945). São Paulo: Rio de Janeiro: Difusão Editorial, 1979.

NICOLINI, A. Qual será o futuro das fábricas de administradores? Revista de Administração de Empresas, v. 43, n. 2, p. 44-54, 2003.

RAJCHMAN, J. Foucault: a ética e a obra. Rencontre Internationale Michel Foucault Philosofe, 9-11 janvier 1989. Paris, Seuil.

RODRIGUES, S. B.; CARRIERI, A. de P. A tradição anglo-saxônica nos estudos organizacionais brasileiros. Revista de Administração Contemporânea, v. 5, Edição Especial, p. 81-102, 2001.

SAES, F. A. M. de; CYTRYNOWICZ, R. O ensino comercial na origem dos cursos superiores de Economia, Contabilidade e Administração. Revista Álvares Penteado, v. 3, n. 6, p. 37-59, 2001.

SCHUCH Jr., V. F. Formação de administradores e mercado de trabalho: um estudo dos egressos do curso de Administração da UFSM e o mercado de trabalho. (Coleção Teses, Dissertações e Monografias). Porto Alegre: UFRGS / PPGA, 1978.

SCHWARTZ, Y. Trabalho e gestão: níveis, critérios, instâncias: In: FIGUEIREDO, M.; ATHAYDE, M.; BRITO, J.; ALVAREZ, D. (Orgs.) Labirintos do Trabalho: interrogações e olhares sobre o trabalho vivo. Rio de Janeiro: DP\&A, 2004.

SILVA, A. A. MÉLLO, R. P. Subjetivação e governamentalidade: questões para a psicologia. Revista de Psicologia, v. 23, n. 2, p. 367-388, 2011.

UNIVERSIDADE FEDERAL DO ESPÍRITO SANTO. Departamento de Administração. Projeto Pedagógico do Curso de Administração. Vitória: UFES, 2010. 


\section{DADOS DOS AUTORES}

\section{SUSANE PETINELLI-SOUZA^ susipetinelli@gmail.com}

\section{Doutora em Educação pela UFES}

Instituição de vinculação: Universidade Federal do Espírito Santo

Vitória/ES - Brasil

Áreas de interesse em pesquisa: Formação e ensino de Administração e gestão, produção de subjetividades, Teoria Organizacional e trabalho.

* Av. Fernando Ferrari, 514, CCJE/Departamento de Administração Vitória/ES 29075-910

O presente trabalho foi realizado com o apoio da CAPES. 